\title{
Frequency of De Quervain's tenosynovitis and its association with SMS texting
}

\author{
Maryam Ali1 \\ Muhammad Asim² \\ Syed Hasan Danish ${ }^{3}$ \\ Farah Ahmad ${ }^{4}$ \\ Afsheen Iqbal ${ }^{5}$ \\ Syed Danish Hasan ${ }^{6}$ \\ 1,2, 5 Ziauddin College of Physiotherapy, Karachi, \\ 3,4 Department of Community Health Sciences, \\ Ziauddin University, Karachi, Pakistan \\ 5 Department of Endocrinology, Metabolism and \\ Lipid Research Washington University School of \\ Medicine, St. Louis, USA \\ 6 Department of Internal Medicine St. Luke's Hos- \\ pital, St. Louis, USA
}

Corresponding author:

Farah Ahmad

Department of Community Health Sciences, Ziauddin University

II/B Block 6 Khayab-e-Ghalib Clifton

74700 Karachi, Pakistan

E-mail: farga24@yahoo.com

\section{Summary}

Objective: to assess the frequency of De Quervain's tenosynovitis and its association with SMS texting. Method: a cross-sectional survey was conducted among undergraduate students studying in different physical therapy schools of Karachi belonging to both public and private sectors. Sample size was 300 students which were selected through convenience sampling. Data was collected through self-administered questionnaire and severity of the pain was assessed through Universal Pain Assessment Tool and De Quervain's tenosynovitis was diagnosed through Finkelstein test. Data entry and analysis were done using computer software SPSS version 20 . Frequency and percentages were taken for categorical variable. Chi-square was applied to determine association between different variables and Finkelstein test. $P$ value $<0.05$ was considered significant.

Results: male/female ratio was 1:4. Regarding the use of cell phones, majority $165(55 \%)$ were using regular cell phones, another $89(30 \%)$ were using touch screen and $38(13 \%)$ were using QWERTY key pads. Almost half of the students were fre- quently using cell phones for texting, out of them $132(44 \%)$ texted less than 50 messages per day. Another 96 (32\%) did texting between 50-100 texts. Out of 300 students who filled the questionnaire $125(42 \%)$ students were experiencing pain in the thumb/wrist. Finkelstein test when done on students almost half $(n=149)$ showed positive results. It was noted that as frequency of mobile phone usage increased progressively more and more people showed positive Finkelstein Test ( $p$ value 0.000 ).

Conclusion: the result of the study concluded that almost half of the students use their mobile phones for texting more than 50 S.M.S per day and because of their mobile key pads and high speed of texting they experienced pain and weakness over the base of the thumb/wrist which shows the De Quervain's positive in that students and there is a positive association between the thumb pain and frequent text messaging.

KEY WORDS: De Quervain's tenosynovitis, Finkelstein test, SMS texting.

\section{Introduction}

Fritz De Quervain was the first in 1895, who defined De Quervain's tenosynovitis as a painful complain of the wrist as stenosing tenosynovitis of thumb abductors around the radiostyloid process ${ }^{1}$. With the new occupational and professional demands the prevalence of this condition is also increasing gradually ${ }^{2}$. The activities which involved the repeated thumb pinching and wrist movement can be the consequence of this painful condition. In the literature search this condition has various synonyms, including De Quervain's disease, first dorsal compartment tenosynovitis, texting tenosynovitis, Blackberry Thumb and Washer Woman's Sprain ${ }^{3,4}$. De Quervain's tenosynovitis is triggered by a stenosing inflammation of the tendon sheath in the first dorsal compartment of the wrist ${ }^{5}$. The patients may experience the associated symptoms beside the pain is dysesthesias, such as numbness, tingling, burning, and cramping ${ }^{6}$. The most standard finding in De Quervain's tenosynovitis is a positive Finkelstein test ${ }^{7}$.

The literature review reveals the precise etiology of De Quervain's tenosynovitis which includes an acute trauma or an extreme, unaccustomed/new exercise. However, more commonly it may be the result of cumulative microtrauma ${ }^{3,8}$. Thus, adults who use their hands and thumb in repetitive manner are more likely to have De Quervain. The patients who experience progressive pain and some degree of limitation 
in deeds, some degree of morbidity may be accompanied with the disease.

According to the latest Pakistan Telecommunication Authority report of December 2009, a total of 106 billion text messages were sent through the 5 cellular networks in Pakistan in 2009. Considering the positive relationship between the thumb pain and frequent text messaging, research on this disease is insignificant to make people aware of the over usage of cell phones and excessive messaging. Previous studies support the fact that text messaging can strongly be related to De Quervain's tenosynovitis. The New Zealand Medical journal refers to it as Texting Tenosynovitis ${ }^{9}$. Even though De Quervain's tenosynovitis is rapidly intensifying problem faced by the young adults, so far, not enough research has been done to support and aware people regarding it. Research on the association of SMS texting and De Quervain's tenosynovitis is scarce in this part of the world and keeping in consideration the popularity of texting among our youth it is justified that a research be conducted to find association between these two entities in young population.

\section{Methodology}

A cross-sectional survey was conducted among undergraduate students studying in different physical therapy schools of Karachi belonging to both public and private sectors.

The intended sample size was 384 students which was calculated by using the standard formula for calculating sample size on the basis of prevalence.

$$
N=\frac{(Z)^{2} \times P(1-P)}{d^{2}}
$$

Prevalence was taken at $50 \%$ because no relevant data was available. The bound of error was taken at $5 \%$ with $95 \%$ confidence level. Actual sample size was 300 students as it was not possible to complete the calculated sample size because of non availabilty of students.

Sample was divided equally between assigned institutes and sample was selected through convenience sampling technique.

Data collection was done by using self-administrated questionnaire. The questions were generally close ended, including information such as type of mobile phone used by the students for text, number of text messages per day, experiencing pain in the thumb/ wrist, swelling or snapping sound over thumb and restriction or pain aggravation while handling different things. In addition to the questionnaire, severity of the pain was assessed through Universal Pain Assessment Tool and De Quervain's tenosynovitis was diagnosed through Finkelstein test.

The participants were instructed to make a fist with the thumb enfolded inside the fingers. The examiner stabilized the forearm and passively deviated the wrist. Pain at the radial wrist, over the Abductor polli- cis longus and Extensor pollicis brevis tendons, a positive test indicated, when it is significantly more tender than the uninvolved side ${ }^{5,10}$.

A written consent was signed by the authorities of institution before the survey was conducted and as quoted by Dr. Padulo in his editorial "Basic principles and recommendation in clinical and field research" informed verbal consent was taken from the study participants according to the "Declaration of Helsinki"11. Data entry and analysis were done using computer software SPSS version 20. Frequency and percentages were taken for categorical variable. Chi-square was applied to determine association between different variables and Finkelstein test. $P$ value $<0.05$ was considered significant.

\section{Results}

Out of the total number of students who participated in the study, $240(80 \%)$ were females and remaining $60(20 \%)$ were males with a male to female ratio of $1: 4$ respectively. Majority were the students of private university studying in four and five year courses of physical therapy.

Regarding the use of cell phones, majority 165 (55\%) were using regular cell phones, another 89 (30\%) were using touch screen and 38 (13\%) were using QWERTY key pads. Most of the participants 282 (94\%) were right handed. Almost half of the students were frequently using cell phones for texting, out of them $132(44 \%)$ texted less than 50 messages per day. Another 96 (32\%) did texting between 50-100 texts, $44(15 \%)$ between $100-200$ and another 28 $(9 \%)$ more than 200 . Twenty-eight students $(9 \%)$ were using internet frequently on their mobile phones while $39(13 \%)$ used their mobile for playing games. Out of 300 students who filled the questionnaire 125 (42\%) students were experiencing pain in the thumb/wrist and another 174 (58\%) students were pain free in which $9(3 \%)$ students gave the history of previous injury and majority 291 (97\%) gave no history of injury. Finkelstein test when done on students almost half $(n=149)$ showed positive results. It was noted that as frequency of mobile phone usage increased progressively more and more people showed positive Finkelstein test ( $p$ value 0.000). An unpredicted result was observed when Finkelstein test was associated with number of text messages per day. Sixty-four (43\%) of those texting within 50-100 messages had positive test however those texting 100-200 messages per day had only $39(26 \%)$ positive results and those students involved in greater than 200 text messages per day displayed only 27 (18\%) positive results (Graph 1). In answer to restrictions to thumb movements only $12(8 \%)$ participants who tested positive showed thumb movement restriction compared to 137 (92\%) who had no issues with thumb movement.

When analyzed for association between Finkelstein test and frequency of texting messages it was observed that 96 (64\%) who used mobile phone for tex- 


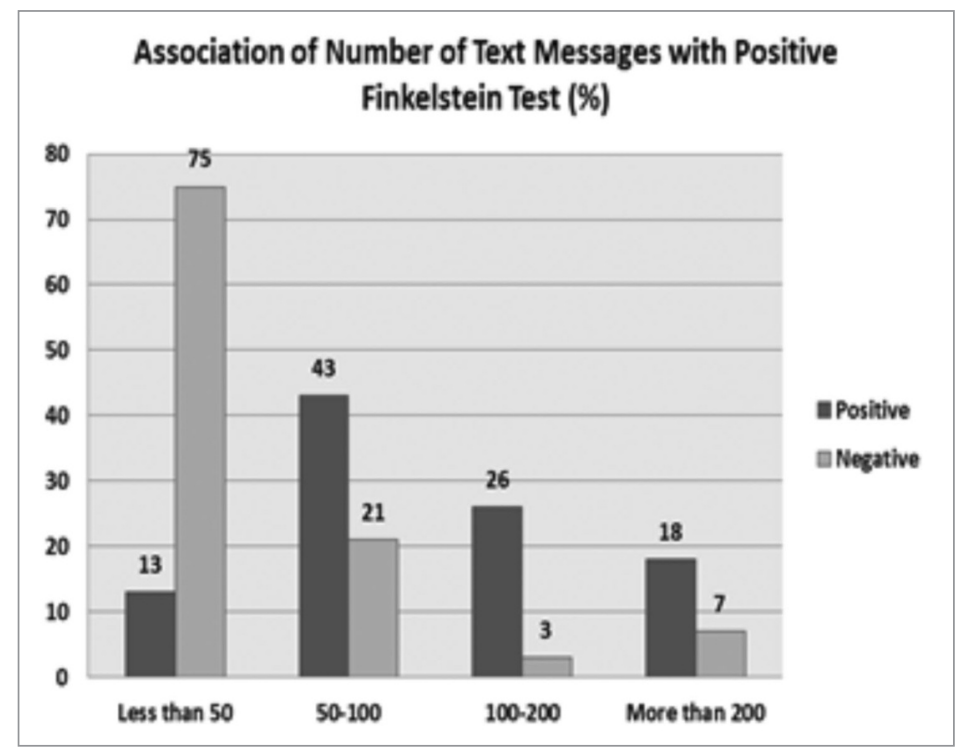

Graph 1. Association of number of text messages with Finkelstein test.

Table 1. Association of Finkelstein Test with thumb movements.

\begin{tabular}{|c|c|c|c|c|c|c|}
\hline \multicolumn{7}{|c|}{ FINKELSTEIN TEST } \\
\hline & & \multicolumn{2}{|c|}{ Positive $(n=149)$} & \multicolumn{2}{|c|}{ Negative $(n=151)$} & \multirow[t]{2}{*}{ P-value } \\
\hline & & $\mathrm{n}$ & $\%$ & $\mathrm{n}$ & $\%$ & \\
\hline \multirow{4}{*}{$\begin{array}{l}\text { How often use mobile } \\
\text { phone for texting }\end{array}$} & Never & 2 & 1 & 0 & 0 & \multirow[t]{4}{*}{0.000} \\
\hline & Rarely & 11 & 7 & 50 & 33 & \\
\hline & Seldom & 40 & 27 & 45 & 30 & \\
\hline & Frequently & 96 & 64 & 56 & 37 & \\
\hline \multirow{4}{*}{$\begin{array}{l}\text { No of text messages } \\
\text { per day }\end{array}$} & Less than 50 & 19 & 13 & 113 & 75 & \multirow[t]{4}{*}{0.000} \\
\hline & $50-100$ & 64 & 43 & 32 & 21 & \\
\hline & $100-200$ & 39 & 26 & 5 & 3 & \\
\hline & More than 200 & 27 & 18 & 1 & 7 & \\
\hline \multirow{2}{*}{$\begin{array}{l}\text { Restriction with } \\
\text { Thumb Movement }\end{array}$} & No & 137 & 92 & 148 & 98 & \multirow[t]{2}{*}{0.016} \\
\hline & Mild & 12 & 8 & 3 & 2 & \\
\hline \multirow{3}{*}{$\begin{array}{l}\text { Difficulty in twisting } \\
\text { keys in past } 2 \text { weeks }\end{array}$} & No difficulty & 132 & 89 & 148 & 98 & \multirow[t]{3}{*}{0.005} \\
\hline & Mild difficulty & 16 & 11 & 3 & 2 & \\
\hline & Moderate difficulty & 1 & 1 & 0 & 0 & \\
\hline \multirow{3}{*}{$\begin{array}{l}\text { Difficulty in opening } \\
\text { the doors in past } \\
2 \text { weeks }\end{array}$} & No difficulty & 142 & 95 & 150 & 99 & \multirow[t]{3}{*}{0.092} \\
\hline & Mild difficulty & 6 & 4 & 1 & 1 & \\
\hline & Moderate difficulty & 1 & 1 & 0 & 0 & \\
\hline \multirow{3}{*}{$\begin{array}{l}\text { Difficulty in buttoning } \\
\text { the shirt in past } 2 \text { weeks }\end{array}$} & No difficulty & 135 & 91 & 150 & 99 & \multirow[t]{3}{*}{0.001} \\
\hline & Mild difficulty & 12 & 8 & 0 & 0 & \\
\hline & Moderate difficulty & 2 & 1 & 1 & 1 & \\
\hline \multirow{3}{*}{$\begin{array}{l}\text { Difficulty in pinching } \\
\text { in past } 2 \text { weeks }\end{array}$} & No difficulty & 132 & 89 & 147 & 97 & \multirow[t]{3}{*}{0.009} \\
\hline & Mild difficulty & 14 & 9 & 4 & 3 & \\
\hline & Moderate difficulty & 3 & 2 & 0 & 0 & \\
\hline \multirow{3}{*}{$\begin{array}{l}\text { Difficulty in unscrewing } \\
\text { jar lid in past } 2 \text { weeks }\end{array}$} & No difficulty & 134 & 90 & 146 & 97 & \multirow[t]{3}{*}{0.064} \\
\hline & Mild difficulty & 12 & 8 & 4 & 3 & \\
\hline & Moderate difficulty & 3 & 2 & 1 & 1 & \\
\hline \multirow{3}{*}{$\begin{array}{l}\text { Difficulty in gripping } \\
\text { in past } 2 \text { weeks }\end{array}$} & No difficulty & 129 & 87 & 146 & 97 & \multirow[t]{3}{*}{0.006} \\
\hline & Mild difficulty & 18 & 12 & 4 & 2 & \\
\hline & Moderate difficulty & 2 & 1 & 1 & 1 & \\
\hline \multirow{4}{*}{$\begin{array}{l}\text { Difficulty in typing on } \\
\text { keyboard in past } \\
2 \text { weeks }\end{array}$} & No difficulty & 111 & 74 & 137 & 90 & \multirow[t]{4}{*}{0.002} \\
\hline & Mild difficulty & 33 & 22 & 11 & 7 & \\
\hline & Moderate difficulty & 4 & 3 & 3 & 2 & \\
\hline & Severe difficulty & 1 & 1 & 0 & 0 & \\
\hline
\end{tabular}


ting were positive for the test compared to $56(37 \%)$ who were negative for Finkelstein test. When different hand movements over the past 2 weeks were compared with Finkelstein test significant $P$ values were observed with certain movements. Twisting of keys showed that out of the total 149 students who had tested positive with Finkelstein test, 132 (89\%) showed no difficulty in twisting keys while $16(11 \%)$ showed mild difficulty $(P$ value $=0.005)$. Difficulty in opening the door showed that only $6(4 \%)$ showed mild difficulty in opening the door. For buttoning the shirt only $12(8 \%)$ showed mild difficulty ( $P$ value $=0.001$ ). Mild difficulty in pinching was observed in $14(9 \%)$ students who tested positive for Finkelstein test $(P$ value $=0.009)$. Difficulty in unscrewing jar lid was observed in $15(10 \%)$ individuals. Another 20 $(13 \%)$ students showed difficulty in gripping $(P$ value $=0.006)$. Significant number of students $38(26 \%)$ had difficulty in typing on key board $(P$ value $=0.002)$ (Tab. 1).

\section{Discussion}

Younger peer group access and exposure to different types of information and communication equipment such as computers and mobile phones has intensely increased over recent years ${ }^{12}$. During the past decade in Sweden only, 15-24-year-age group have $100 \%$ access to mobile phones and $93 \%$ on average utilize it for sending text messages $(S M S)^{13}$. Use of mobile phones has increased in USA in teens for text messaging from $38 \%$ in 2008 to $54 \%$ in $2009^{14}$. When considering students related to healthcare profession most common reasons related to SMS texting include academic related activities ${ }^{15}$. De Quervain's tenosynovitis most commonly arises due to the overuse of the thumb musculature which is characterized by pain that spread over the surface of radial aspect of the wrist and intensified by ulnar deviation of the hand ${ }^{16}$. The prevalence of this condition upturns with new occupational demands such as extended work at computer, an athlete especially who follows a high resistance training that includes lifting weight and using hands for support and maximal exertion ${ }^{10}$.

In 2010, a case report of bilateral De Quervain's tenosynovitis revealed that the diagnosis linked the patient's condition with excessive routine of the text messaging feature on a cellular telephone ${ }^{16}$.

An extensive community based study performed in United Kingdom displayed that prevalence of de Quervain's tenosynovitis was $0.5 \%$ in males compared to $1.3 \%$ in females ${ }^{17}$. In 2007 , The Newzealand Medical Journal published an article on texting tenosynovitis where they figured two previous reports of texting tenosynovitis ${ }^{18}$.

Our study results were unusual in that $43 \%$ of those texting between 50-100 SMS had positive Finkelstein test and as texting increased prevalence of the condition decreased. This was contrary to the results shown by Yoong who witnessed this condition in school children in Singapore who were sending more than 100 text messages per day ${ }^{18}$. However similar observation to our research was seen in a study conducted by Lenhart et al., with $50 \%$ positive results for those texting 50 messages and $33 \%$ positive results among those going for 100 text messages per day ${ }^{14}$. Our results were significant when different hand movements were compared to results of the Finkelstein test. This was in accordance to previous literature that explicitly states repetitive pushing, prolonged and sustained gripping (example during computer use or hand tool use) and repetitive redundant movements of the thumb (e.g. typing) as potential risk factors ${ }^{19,20}$.

Other studies have purported these results with patients complaining of decrease in gripping strength, pain in wrist while using thumb and as a consequence dropping objects due to pain or stating a combination of these symptoms ${ }^{21}$.

Our survey although scarcely performed in our part of the world had few limitations. First the male to female ratio was unequivalent with a preponderance of females. Studies have pointed that prevalence of De Quervain's tenosynovitis remains higher in females ${ }^{3}$. A variety of mobile phones were used by participants differing in size and weight that may have produced varied results. Also posture while texting was never noted. Studies have stated difference of results for those messaging while standing compared to sitting as it creates a different impact on the muscles of upper limb, with more exertion on muscles while standing during messaging ${ }^{22}$. Confounders like playing games on mobiles, typing on laptops were not taken into detail that may have biased the results ${ }^{23}$. As this was a cross sectional study differences and impacts of texting techniques could not be assessed which according to previous literature causes effect on the occurrence of the disorder and is different for symptomatic versus asymptomatic patients ${ }^{24}$.

However, our strengths cannot be overlooked. Unfortunately there is no gold standard diagnostic confirmatory test for De Quervain's tenosynovitis ${ }^{25}$. Results of the Finkelstein test are deemed pathognomic for De Quervain's tenosynovitis $21,26,27$. To minimize inter observer variation every participant was examined twice by the primary investigators themselves. According to studies a positive Finkelstein's test has a intra observer repeatability $(k)$ of $0.79^{28}$. Refusal rate by the participants were negligible. Sample size was representative of both public and private sector universities. Universal Pain Assessment Tool was utilized for assessing the severity of pain.

In the $21^{\text {st }}$ century mobile phones have become more of a necessity than a luxury ${ }^{29}$. With the dawn of smartphones and advance versions expected in future it is inevitable that diseases related to extensive use of cell phones will increase in numbers specifically musculoskeletal problems. The main brunt will be faced by the younger generation who are still in the phase of development and are prone to extensive use through short message service (SMS) messaging 
and gaming ${ }^{24}$. In order to inhibit the development of musculoskeletal disorders, a better understanding of the texting technique and connection to the muscle activity and the kinematics is needed. As De Quervain's tenosynovitis is a serious issue leading to dysfunction of the affected hand further insight would help researchers to get a background for physical guidelines for texting on mobile phones and recommend appropriate behavioral changes for averting this under recognized cause of tendinopathy.

\section{Conclusion}

The result of the study concluded that almost half of the students use their mobile phones for texting more than 50 SMS per day and because of their mobile key pads and high speed of texting they experienced pain and weakness over the base of the thumb/wrist which shows the De Quervain's positive in that students and there is a positive association between the thumb pain and frequent text messaging.

This research will advise mobile phone users to text with both hands, take frequent breaks, not type too fast and to give proper support to their forearms and back while texting.

\section{References}

1. Davis RV. Management of de Quervain's Disease Chiroweb Archives. 1992.

2. Foye PM, Cianca JC, Prather H. 3. Cumulative trauma disorders of the upper limb in computer users. Archives of physical medicine and rehabilitation. 2002;83:S12-S5.

3. Foye P, Stitik T. De Quervain Tenosynovitis. eMedicine [database online] Omaha (NE): eMedicine com, Inc. 2008;13.

4. Souza TA. Differential diagnosis for the chiropractor: protocols and algorithms: Aspen Publishers. 1997.

5. Moore K. Clinically Oriented Anatomy (ed 3) Williams and Wilkins. Baltimore, MD. 1992;342-343.

6. Berkow R, Fletcher AJ, Bondy PK. The Merck manual of diagnosis and therapy. 1992.

7. Magee DJ. Forearm, wrist and hand. Orthopedic physical assessment. 5th edition St Louis, MO: Saunders Elsevier. 2008;396-470.

8. Avci S, Yilmaz C, Sayli U. Comparison of nonsurgical treatment measures for de Quervain's disease of pregnancy and lactation. The Journal of hand surgery. 2002;27(2):322-324.

9. Sivapragasam N, editor. The Future of the Public Phone: Findings from a six-country Asian study of telecom use at the BOP. 4th Communication Policy Research, South Conference, Negombo, Sri Lanka. 2009.

10. Pagonis T, Ditsios K, Toli P, Givissis P, Christodoulou A. Improved corticosteroid treatment of recalcitrant de Quervain tenosynovitis with a novel 4-point injection technique. The American Journal of Sports Medicine. 2011;39(2):398-403.

11. Padulo J, Oliva F, Frizziero A, Maffulli N. Muscle, Ligaments and Tendons Journal. Basic principles and recommendations in clinical and field science research. MLTJ. 2013;4:250-252.

12. Mezei G, Benyi M, Muller A. Mobile phone ownership and use among school children in three Hungarian cities. Bioelectromagnetics. 2007;28(4):309-315.

13. Gustafsson $E$, Johnson PW, Lindegård A, Hagberg M. Technique, muscle activity and kinematic differences in young adults texting on mobile phones. Ergonomics. 2011; 54(5): 477-487.

14. Lenhart A, Purcell K, Smith A, Zickuhr K. Social media \& mobile internet use among teens and young adults: Pew internet \& american life project Washington, DC; 2010.

15. Jones M, Marsden G. "Please turn ON your mobile phone"First Impressions of Text-messaging in Lectures: Springer. 2004.

16. Ashurst JV, Turco DA, Lieb BE. Tenosynovitis caused by texting: an emerging disease. JAOA: Journal of the American Osteopathic Association. 2010;110(5):294-296

17. Walker-Bone K, Palmer KT, Reading I, Coggon D, Cooper C. Prevalence and impact of musculoskeletal disorders of the upper limb in the general population. Arthritis Care \& Research. 2004;51(4):642-651.

18. Yoong J. Mobile phones can be a pain-text messaging tenosynovitis. Hospital medicine (London, England: 1998). 2005;66(6):370.

19. Gupta AD, Mahalanabis D. Study of hand function in a group of shoe factory workers engaged in repetitive work. Journal of occupational rehabilitation. 2006; 16(4):675-684.

20. Barr AE, Barbe MF, Clark BD. Work-related musculoskeletal disorders of the hand and wrist: epidemiology, pathophysiology, and sensorimotor changes. The Journal of orthopaedic and sports physical therapy. 2004;34(10):610.

21. Bruckschwaiger O. Atypical De Quervain's Disease. Canadian Medical Association Journal. 1954;71(3):277.

22. Mork PJ, Westgaard RH. The influence of body posture, arm movement, and work stress on trapezius activity during computer work. European journal of applied physiology. 2007;101(4):445-456.

23. Anderson SE, Steinbach LS, De Monaco D, Bonel HM, Hurtienne $Y$, Voegelin E. "Baby wrist": MRI of an overuse syndrome in mothers. American Journal of Roentgenology. 2004;182 (3):719-724.

24. Gustafsson E, Johnson PW, Hagberg M. Thumb postures and physical loads during mobile phone use-A comparison of young adults with and without musculoskeletal symptoms. Journal of Electromyography and Kinesiology. 2010;20 (1):127-135.

25. Sluiter JK, Rest KM, Frings-Dresen MH. Criteria document for evaluating the work-relatedness of upper-extremity musculoskeletal disorders. Scandinavian journal of work, environment \& health. 2001;1-102.

26. Keon-Cohen B. De Quervain's disease. J Bone Joint Surg Br. 1951;33:96-99.

27. Kamel M, Moghazy K, Eid H, Mansour R. Ultrasonographic diagnosis of de Quervain's tenosynovitis. Annals of the rheumatic diseases. 2002;61(11):1034-1035.

28. Palmer K, Walker-Bone K, Linaker C, Reading I, Kellingray S, Coggon D, et al. The Southampton examination schedule for the diagnosis of musculoskeletal disorders of the upper limb. Annals of the rheumatic diseases. 2000;59(1):5-11.

29. Gordon S. Beware the 'Blackberry Thumb'. The Washington Post. 2008. 